\title{
Validitas Hasil Pemeriksaan Skin Prick Test terhadap Imunoglobulin E RAST Tungau Debu Rumah dan Debu Rumah pada Dermatitis Atopik
}

\author{
Yeyen Yovita Mulyana, ${ }^{1}$ Endang Sutedja, ${ }^{1}$ Oki Suwarsa ${ }^{2}$ \\ ${ }^{1}$ Siloam Hospital Jakarta, ${ }^{2}$ Departemen Ilmu Kesehatan Kulit \& Kelamin Fakultas Kedokteran \\ Universitas Padjadjaran-Rumah Sakit Dr. Hasan Sadikin Bandung
}

\begin{abstract}
Abstrak
Pada dermatitis atopik (DA) tipe ektrinsik terdapat peningkatan imunoglobulin E (IgE) spesifik terhadap tungau debu rumah (TDR) dan debu rumah (DR) dengan gambaran skin prick test (SPT) positif. Metode penelitian observasional analitik dengan rancangan studi potong lintang, bertujuan untuk mengetahui validitas hasil pemeriksaan SPT terhadap IgE radioallergosorbent testing (RAST) TDR dan DR pada penderita DA, supaya SPT dapat diaplikasikan untuk mendeteksi DA. Penelitian dilakukan selama Agustus-November 2011 di Poliklinik Departemen Ilmu Kesehatan Kulit dan Kelamin RS Dr. Hasan Sadikin Bandung. Uji statistik menggunakan Spearman's rank correlation. Hasil penelitian menunjukkan SPT TDR yang positif pada DA lebih tinggi dibandingkan dengan non-DA secara statistik bermakna, sedangkan SPT DR yang positif pada DA lebih tinggi dibandingkan dengan non-DA secara statistik tidak bermakna. Nilai positivitas SPT dan IgE RAST terhadap TDR pada DA berbanding lurus, namun tidak terhadap DR. Nilai positivitas SPT TDR pada DA lebih tinggi $(15 / 16)$ daripada non-DA (5/16) dan nilai positivitas SPT TDR berbanding lurus dengan IgE RAST TDR pada DA dengan Spearman's rank correlation coefficient $0,541(\mathrm{p}=0,031)$. Hasil pemeriksaan SPT TDR terhadap IgE RAST TDR pada kelompok DA memberikan validitas yang lebih tinggi dengan sensitivitas $100 \%$, spesifisitas $25 \%$, dan akurasi 81\%, dibandingkan SPT DR terhadap IgE RAST DR dengan sensitivitas 43\%, spesifisitas 78\%, dan akurasi 63\%. Simpulan, pemeriksaan SPT TDR dapat dijadikan patokan diagnosis DA, karena hasil pemeriksaan SPT TDR yang positif dapat memberikan arti peningkatan IgE spesifik dengan pemeriksaan IgE RAST TDR. [MKB. 2012;44(3):186-91].
\end{abstract}

Kata kunci: Debu rumah, dermatitis atopik, IgE RAST, skin prick test, tungau debu rumah

\section{Validity of Skin Prick Test toward House Dust Mite and House Dust Immunoglobulin E RAST in Atopic Dermatitis}

\begin{abstract}
In extrinsic type atopic dermatitis (AD) there is an increased of specific immunoglobulin (IgE) towards house dust mites (HDM) and house dust (HD), resulting in positive skin prick test (SPT). The method of this study was cross sectional, analytic-observational, to find validity of SPT toward HDM and HD IgE radioallergosorbent (RAST) in AD patients. The study was held from August to November 2011 in Department of Dermatovenereology Dr. Hasan Sadikin Hospital Bandung. Spearman's rank correlation coefficient was used for statistical analysis. The results showed positive SPT to HDM in AD patients were statistically significant higher than non-AD. Positive SPT to HD in AD patients were higher than non-AD but statistically non significant. Value of HDM SPT positivity and IgE RAST in AD was directly proportional, but not with HD. There was a higher positivity of HMD SPT in AD patients $(15 / 16)$ than in non-AD $(5 / 16)$. Positivity value of HDM SPT was proportional to the HDM IgE RAST in AD patients with Spearman's Rank correlation coefficient $0.541(\mathrm{p}=0.031)$. The results of HDM SPT toward HDM IgE RAST in AD patients showed higher validity sensitivity, specificity, and accuracy, $100 \%, 25 \%$ and $81 \%$ respectively, while HD SPT toward HD IgE RAST with sensitivity, specificity, and accuracy 43\%, 78\% and 63\% respectively. In conclusions, HDM TDR examination could be used as a marker for AD diagnosis, due to positive HDM TDR examination result could give a meaning of increased specific IgE with RAST IgE examination. [MKB. 2012;44(3):186-91].
\end{abstract}

Key words: Atopic dermatitis, house dust, house dust mites, IgE RAST, skin prick test

Korespondensi: Yeyen Yovita Mulyana, Siloam Hospital, jalan Raya Perjuangan kav. 8 Kebon Jeruk Jakarta Barat, mobile 081220217000,e-mail dr_yeyen@yahoo.co.id 


\section{Pendahuluan}

Dermatitis atopik (DA) merupakan penyakit peradangan kulit yang bersifat kronik, residif, ${ }^{1}$ dapat mengenai semua usia, berhubungan dengan stigmata atopi lainnya, ${ }^{2,3}$ seperti rinitis alergika $(35 \%)$ dan asma $(30 \%))^{2}$ Patogenesis DA bersifat multifaktorial, berhubungan dengan interaksi kompleks faktor genetik yang menyebabkan gangguan fungsi sawar kulit, faktor lingkungan seperti paparan alergen tungau debu rumah (TDR) dan debu rumah (DR), dan terjadinya respons imun. ${ }^{1,4}$ Fungsi sawar kulit yang menurun pada DA memudahkan TDR dan DR masuk ke dalam epidermis. ${ }^{1,2}$ Alergen inhalan seperti TDR, bulu binatang, serbuk sari, dan kapang paling sering ditemukan sebagai pencetus terjadinya DA, yaitu sekitar $70 \%$ penderita DA. ${ }^{2}$

Alergen yang terdapat pada DR dan TDR dapat merusak sawar epidermal dengan bantuan protease eksogen, hal ini diperberat pada kulit penderita DA dengan kadar inhibitor protease yang kurang, sehingga akan terjadi penyerapan alergen ke dalam kulit dan menimbulkan respons imun. ${ }^{1}$ Suwarsa ${ }^{5}$ melaporkan $90 \%$ penderita DA menunjukkan respons hipersensitivitas terhadap TDR. Jenis TDR yang sering berhubungan dengan DA yaitu Dermatophagoides pteronyssinus (Der $p$ ) dan Dermatophagoides farinae (Der f) ${ }^{6,7}$

Dermatitis atopik dibagi menjadi dua jenis, yaitu DA tipe alergik/ekstrinsik dan DA tipe nonalergik/intrinsik. Pada orang dewasa dengan DA, $70-80 \%$ merupakan tipe ekstrinsik, ketika terdapat paparan terhadap alergen lingkungan akan meningkatkan imunoglobulin $\mathrm{E}$ total serum (IgE total).8,9

Manifestasi klinis pada penderita DA setelah paparan aeroalergen memperlihatkan respons hipersensitivitas tipe I dalam etiopatogenesis DA yang dapat dideteksi dengan pemeriksaan IgE spesifik atau skin prick test (SPT) ${ }^{8}$ Imunoglobulin E spesifik dideteksi dengan radioallergosorbent testing (RAST). Konsentrasi IgE spesifik paling besar pada penderita DA yaitu IgE terhadap TDR, terutama Der $p .{ }^{10}$ Skin prick test tergolong pemeriksaan alergi yang murah, dapat dipercaya, cepat, serta aman. ${ }^{11}$ Pemilihan IgE RAST atau SPT sebagai metode diagnosis suatu alergi yaitu berdasarkan ketersediaan sarana, biaya, dan risiko ketidaknyamanan bagi penderita, namun kedua pemeriksaan ini dapat dikombinasikan dengan anamnesis untuk mendiagnosis suatu alergi.?

Penelitian ini bertujuan untuk mengetahui validitas hasil pemeriksaan SPT terhadap $\operatorname{IgE}$ RAST TDR dan DR pada penderita DA, supaya SPT dapat diaplikasikan untuk mendeteksi DA.

\section{Metode}

Penelitian ini berupa penelitian observasional analitik dengan rancangan studi potong lintang, yaitu dengan melakukan SPT dan pengukuran kadar IgE RAST terhadap TDR dan DR pada kelompok kasus dan kontrol.

Subjek penelitian penderita dermatitis atopik yang berobat ke Poliklinik Departemen Ilmu Kesehatan Kulit dan Kelamin Rumah Sakit Dr. Hasan Sadikin (RSHS) Bandung yang memenuhi kriteria inklusi, yaitu penderita DA (laki-laki dan perempuan) berusia di atas 12 tahun yang didiagnosis berdasarkan kriteria Hanifin-Rajka. Kelompok kontrol yaitu kelompok non-DA (tidak memenuhi kriteria Hanifin-Rajka) dan memenuhi kriteria inklusi. Semua subjek penelitian bersedia mengikuti penelitian dengan menandatangani persetujuannya (informed consent). Penelitian ini telah mendapat persetujuan dari Komite Etik Penelitian Kesehatan Fakultas Kedokteran Universitas Padjadjaran-Rumah Sakit Dr. Hasan Sadikin Bandung. Pemilihan subjek dilakukan dengan cara consecutive sampling. Besar sampel ditentukan berdasarkan penghitungan analisis korelasi dengan memilih taraf kepercayaan 95\% dan power test $80 \%$, serta besarnya koefisien korelasi antara IgE RAST dan SPT $(\mathrm{r}=-0,64)$ yang diperoleh dari penelitian Witteman dkk. ${ }^{12}$ sehingga didapatkan $n=16$. Pada penelitian ini terdapat 2 kelompok, yaitu kelompok DA dan kelompok kontrol, maka diperlukan 32 sampel (16 sampel untuk kelompok DA dan 16 sampel untuk kelompok kontrol).

Analisis data menggunakan uji MannWhitney untuk membandingkan perbedaan skor median antara dua kelompok, uji chikuadrat atau uji eksak Fisher untuk menganalisis hubungan dua variabel. Korelasi rank Spearman digunakan untuk analisis hubungan dua variabel dengan skala ordinal dengan kriteria koefisien korelasi: $\quad$ rs $<0,4=$ lemah; $0,4<$ rs $<0,6=$ sedang; $0,6<\mathrm{rs}<0,8=$ kuat; dan $\mathrm{rs}>0,8=$ sangat kuat. Untuk mengetahui validitas hasil pemeriksaan SPT terhadap IgE RAST TDR dan DR dihitung besarnya sensitivitas, spesifisitas, dan akurasi.

Waktu penelitian selama Agustus-November 2011. Pemeriksaan klinis dan SPT dilakukan di Poliklinik Departemen Ilmu Kesehatan Kulit dan Kelamin Divisi Alergi-Imunologi RSHS Bandung, sedangkan pemeriksaan kadar IgE RAST dilakukan di Laboratorium Pramita Jalan Martadinata nomor 135 Bandung.

\section{Hasil}

Karakteristik subjek penelitian meliputi usia dan jenis kelamin pada kelompok DA dan non-DA 
Yeyen Yovita Mulyana: Validitas Hasil Pemeriksaan Skin Prick Test terhadap Imunoglobulin E RAST Tungau Debu Rumah

Tabel 1 Karakteristik Subjek Penelitian Kelompok DA dan Non-DA

\begin{tabular}{cccc}
\hline Karakteristik & \multicolumn{2}{c}{ Kelompok } & Kemaknaan \\
\cline { 2 - 3 } & $\begin{array}{c}\text { DA } \\
(\mathbf{n}=\mathbf{1 6})\end{array}$ & $\begin{array}{c}\text { Non-DA } \\
(\mathbf{n}=\mathbf{1 6})\end{array}$ & \\
\hline Usia (tahun) & & & $\mathrm{t}=0,246$ \\
$\bar{X}$ (SD) & 25,9 & 25,2 & $\mathrm{p}=0,808$ \\
Median & 23,5 & 22 & \\
Rentang & $14-41$ & $12-45$ & $\mathrm{X}^{2}=0$ \\
Jenis kelamin & & & $\mathrm{p}=1,0$ \\
Laki-laki & 4 & 12 & \\
Perempuan & 12 & &
\end{tabular}

Keterangan: $\mathrm{t}=$ uji $\mathrm{t}, \mathrm{X}^{2}=$ uji chi-kuadrat

tidak menunjukkan perbedaan yang bermakna ( $>00,05)$, dengan demikian maka kedua kelompok komparabel atau layak diperbandingkan (Tabel 1). Skin prick test TDR pada kelompok DA median +3 sedangkan non-DA adalah negatif, perbedaan ini secara statistik sangat bermakna, sedangkan SPT DR median pada kedua kelompok sama (negatif) sehingga tidak bermakna (Tabel 2). Dari hasil positivitas, SPT TDR pada kelompok DA menunjukkan hasil yang sangat bermakna bila dibandingkan dengan kelompok kontrol $(\mathrm{p}<0,001)$. Positivitas SPT TDR pada kelompok DA 94\% dan kelompok non-DA 31,2\%.

Imunoglobulin E RAST berdasarkan kelas kelompok TDR menunjukkan perbedaan yang sangat bermakna pada kedua kelompok dengan $\mathrm{p}=0,004$, sedangkan pada kelompok DR tidak bermakna dengan $\mathrm{p}=0,090$ (Tabel 3). Positivitas IgE RAST TDR pada kelompok DA $75 \%$ dan kelompok non-DA $50 \%$, sedangkan positivitas IgE RAST DR menunjukkan nilai yang lebih rendah yaitu $44 \%$ pada kelompok DA dan $6 \%$ pada kelompok non-DA.

Terdapat korelasi positif yang bermakna hasil pemeriksaan SPT TDR dengan IgE RAST TDR pada kelompok DA, sedangkan pada kelompok non DA tidak berhubungan (Tabel 4). Korelasi lain yang bermakna yaitu antara hasil pemeriksaan SPT TDR dan SPT DR baik pada kelompok DA maupun non-DA dengan besarnya koefisien korelasi rank Spearman 0,609 $(\mathrm{p}=0,012)$ dan $0,904(\mathrm{p}<0,001)$.

Tabel 2 Perbandingan SPT TDR dan SPT DR pada Kelompok DA dan Non-DA

\begin{tabular}{|c|c|c|c|c|}
\hline \multirow[b]{2}{*}{ Hasil Penelitian } & \multicolumn{2}{|c|}{ Kelompok } & \multirow[b]{2}{*}{$\mathbf{Z}_{\text {мW }}$} & \multirow[b]{2}{*}{$\mathbf{p}$} \\
\hline & $\begin{array}{c}\text { DA } \\
(n=16)\end{array}$ & $\begin{array}{c}\text { Non-DA } \\
(n=16)\end{array}$ & & \\
\hline \multicolumn{5}{|l|}{ SPT TDR } \\
\hline- & 1 & 11 & & \\
\hline+1 & 0 & 2 & & \\
\hline+2 & 0 & 2 & & \\
\hline$+\overline{3}$ & 10 & 1 & & \\
\hline+4 & 5 & 0 & & \\
\hline Median & +3 & - & 4,461 & $<0,001$ \\
\hline Rentang & - s.d. +4 & - s.d. +3 & & \\
\hline Positivitas SPT TDR & $\begin{array}{c}15 \\
1\end{array}$ & $\begin{array}{c}5 \\
11\end{array}$ & $X^{2}=13,33$ & $<0,001$ \\
\hline \multicolumn{5}{|l|}{ SPT DR } \\
\hline- & 11 & 12 & & \\
\hline+1 & 2 & 2 & & \\
\hline+2 & 2 & 2 & & \\
\hline+3 & 0 & 0 & & \\
\hline+4 & 1 & 0 & & \\
\hline Median & - & - & 0,477 & 0,724 \\
\hline Rentang & - s.d. +4 & - s.d. +2 & & \\
\hline Positivitas DR & $\begin{array}{c}5 \\
11\end{array}$ & $\begin{array}{c}4 \\
12\end{array}$ & & $\mathrm{p}_{\mathrm{EF}}=1,0$ \\
\hline
\end{tabular}

Keterangan: Z MW = uji Mann-Whitney 
Tabel 3 Perbandingan Kadar IgE RAST pada Kelompok DA dengan Non-DA

\begin{tabular}{cccc}
\hline IgE RAST & \multicolumn{2}{c}{ Kelompok } & \multirow{2}{*}{ Kemaknaan } \\
\cline { 2 - 3 } & $\begin{array}{c}\text { DA } \\
(\mathbf{n}=\mathbf{1 6})\end{array}$ & $\begin{array}{c}\text { Non-DA } \\
(\mathbf{n}=\mathbf{1 6})\end{array}$ & \\
\hline TDR: Negatif & 4 & 8 & $\mathrm{X}^{2}=13,11$ \\
Kelas I & 2 & 7 & $\mathrm{p}=0,004$ \\
Kelas II & 1 & 1 & \\
$\geq$ Kelas III & 9 & 0 & \\
Positivitas IgE RAST TDR: & & & $\mathrm{X}^{2}=2,13$ \\
+ & 12 & 8 & $\mathrm{p}=0,144$ \\
- & 4 & 8 & \\
DR: Negatif & 9 & 15 & $\mathrm{X}^{2}=6,50$ \\
Kelas I & 3 & 0 & $\mathrm{p}=0,090$ \\
Kelas II & 3 & 1 & \\
$\geq$ Kelas III & 1 & 0 & $\mathrm{p}_{\mathrm{EF}}=0,037$ \\
\hline Positivitas IgE RAST DR: & 7 & 1 & \\
+ & 9 & 15 &
\end{tabular}

Keterangan: $\mathrm{pEF}=\mathrm{p}$ berdasarkan uji eksak Fisher

Tabel 4 Korelasi antara Hasil Pemeriksaan SPT dan IgRAST

\begin{tabular}{lcccc}
\hline \multirow{2}{*}{ Korelasi } & \multicolumn{2}{c}{ Kelompok DA } & \multicolumn{2}{c}{ Kelompok Non-DA } \\
\cline { 2 - 5 } & $\mathbf{r}_{\mathrm{s}}$ & $\mathbf{p}$ & $\mathbf{r}_{\mathrm{s}}$ & $\mathbf{p}$ \\
\hline SPT TDR dengan IgE RAST TDR & 0,541 & 0,031 & 0,065 & 0,810 \\
SPT TDR dengan SPT DR & 0,609 & 0,012 & 0,904 & $<0,001$ \\
SPT DR dengan IgE RAST DR & 0,058 & 0,832 & $-0,148$ & 0,584 \\
\hline
\end{tabular}

Keterangan: *) uji 1 pihak, rs=koefisien korelasi rank Spearman

Sensitivitas SPT TDR yang sangat tinggi pada kelompok DA (100\%) dengan spesifisitas $25 \%$ dan akurasi $81 \%$, sedangkan SPT DR pada kelompok DA mempunyai sensitivitas yang rendah sebesar $43 \%$, spesifisitas $78 \%$, dan akurasi 63\% (Tabel 5, Tabel 6). Hasil pemeriksaan SPT TDR pada kelompok DA menunjukkan validitas yang lebih tinggi dibandingkan dengan SPT DR.

\section{Pembahasan}

Berdasarkan studi epidemiologi, DA lebih banyak

Tabel 5 Validitas Hasil Pemeriksaan SPT TDR terhadap IgE RAST TDR

\begin{tabular}{|c|c|c|c|c|c|c|}
\hline \multirow[t]{2}{*}{ Kelompok } & \multicolumn{2}{|c|}{$\begin{array}{c}\text { IgE RAST } \\
\text { TDR }\end{array}$} & \multirow{2}{*}{$\begin{array}{c}\text { Sensitivitas } \\
(\%)\end{array}$} & \multirow{2}{*}{$\begin{array}{c}\text { Spesifisitas } \\
(\%)\end{array}$} & \multirow{2}{*}{$\begin{array}{c}\text { Akurasi } \\
(\%)\end{array}$} & \multirow[t]{2}{*}{$\mathbf{p}^{*}$} \\
\hline & + & - & & & & \\
\hline \multicolumn{7}{|l|}{ DA } \\
\hline $\begin{array}{r}\text { SPT TDR + } \\
-\end{array}$ & $\begin{array}{r}12 \\
0\end{array}$ & $\begin{array}{l}3 \\
1\end{array}$ & 100 & 25 & 81 & $>0,05$ \\
\hline \multicolumn{7}{|l|}{ Non-DA } \\
\hline SPT TDR + & $\begin{array}{l}3 \\
5\end{array}$ & $\begin{array}{l}2 \\
6\end{array}$ & 38 & 75 & 56 & $>0,05$ \\
\hline $\begin{array}{l}\text { Gabungan } \\
+ \\
+\end{array}$ & $\begin{array}{r}15 \\
5\end{array}$ & $\begin{array}{l}5 \\
7\end{array}$ & 75 & 58 & 69 & \\
\hline
\end{tabular}

Keterangan: *)berdasarkan uji Mc Nemar 
Tabel 6 Validitas Hasil Pemeriksaan SPT DR terhadap IgE RAST DR

\begin{tabular}{|c|c|c|c|c|c|c|}
\hline \multirow{2}{*}{ Kelompok } & \multicolumn{2}{|c|}{ IgE RAST DR } & \multirow{2}{*}{$\begin{array}{c}\text { Sensitivitas } \\
(\%)\end{array}$} & \multirow{2}{*}{$\begin{array}{c}\text { Spesifisitas } \\
(\%)\end{array}$} & \multirow{2}{*}{$\begin{array}{c}\text { Akurasi } \\
(\%)\end{array}$} & \multirow[t]{2}{*}{$\mathbf{p}^{*}$} \\
\hline & + & - & & & & \\
\hline \multicolumn{7}{|l|}{ DA } \\
\hline SPT DR + & 3 & 2 & 43 & 78 & 63 & $>0,05$ \\
\hline- & 4 & 7 & & & & \\
\hline \multicolumn{7}{|l|}{ Non-DA } \\
\hline SPT DR + & 0 & 4 & 0 & 73 & 69 & $>0,05$ \\
\hline- & 1 & 11 & & & & \\
\hline \multicolumn{7}{|l|}{ Gabungan } \\
\hline+ & 3 & 6 & 38 & 75 & 66 & \\
\hline- & 5 & 18 & & & & \\
\hline
\end{tabular}

Keterangan: *) berdasarkan uji Mc Nemar

mengenai perempuan daripada laki-laki, dengan perbandingan 1,3-1,5:1.1 Dalam penelitian Darsow dkk. ${ }^{13}$ terdapat 314 penderita DA, 177 perempuan dan 137 laki-laki dengan rentang usia 1,6-80 tahun. Suwarsa ${ }^{5}$ melaporkan bahwa dari 20 penderita DA, terdapat 13 orang perempuan dan 7 orang laki-laki dengan rentang usia $7-55$ tahun. Pada penelitian ini jumlah subjek penelitian kelompok DA sama dengan kelompok non-DA dengan jenis kelamin terbanyak perempuan dan rentang usia yang serupa antara kedua kelompok. Berdasarkan data tersebut maka jenis kelamin dan usia subjek penelitian ini tidak berbeda dengan penelitian lain sebelumnya.

Hasil SPT positif merupakan salah satu kriteria minor untuk mendiagnosis DA menurut Hanifin-Rajka. ${ }^{14}$ Suwarsa ${ }^{5}$ melaporkan bahwa SPT TDR 90\% positif pada kelompok DA, sedangkan pada kelompok kontrol sebesar $45 \%$, berdasarkan uji statistik didapatkan perbedaan yang bermakna. Pada penelitian ini juga tampak hasil pemeriksaan SPT TDR pada kelompok DA dan non-DA memiliki perbedaan yang sangat bermakna secara statistik $(\mathrm{p}<0,001)$, terdapat 15/16 penderita DA menunjukkan hasil SPT TDR positif, dan hanya 5/16 subjek dari kelompok kontrol yang menunjukkan SPT TDR positif (Tabel 2). Data penelitian ini sesuai dengan teori yang mengungkapkan sekitar $85 \%$ penderita DA mempunyai hasil positif terhadap SPT TDR. ${ }^{7}$ Kelompok DA mempunyai hasil SPT TDR yang lebih tinggi dibandingkan dengan kelompok nonDA, sehingga pemeriksaan SPT TDR ini dapat digunakan untuk menilai sensitisasi seseorang terhadap TDR karena mempunyai nilai positivitas yang tinggi.

Skin prick test DR pada kelompok DA dan kelompok non-DA tidak menunjukkan perbedaan yang bermakna $(p>0,05)$ (Tabel 2). Data yang sama ditunjukkan pula dalam penelitian Suwarsa ${ }^{5}$ pada hasil SPT DR (alergen hirup selain TDR dan alergen makanan) berdasarkan uji statistik tidak terdapat perbedaan yang bermakna antara kelompok DA dan kelompok kontrol. Nilai positivitas SPT TDR lebih tinggi dibandingkan dengan SPT DR pada kelompok DA. Hal ini mungkin disebabkan perbedaan konsentrasi alergen TDR dengan DR. Tingkat paparan alergen DR dapat diperkirakan berdasarkan konsentrasi TDR yang terdapat di dalam DR, sehingga dapat disimpulkan konsentrasi TDR yang lebih besar memberikan nilai positif SPT yang lebih tinggi. ${ }^{15}$

Imunoglobulin E RAST berdasarkan kelas kelompok TDR menunjukkan perbedaan sangat bermakna pada kelompok DA dan non-DA, sehingga dapat disimpulkan bahwa kelompok DA memiliki kelas IgE RAST TDR yang lebih tinggi dibandingkan dengan kelompok non-DA (Tabel 3). Penelitian ini menunjang teori bahwa 95\% serum penderita DA memiliki IgE spesifik terhadap TDR. ${ }^{1}$ Hasil pemeriksaan IgE RAST DR pada kelompok DA dan kelompok non-DA menunjukkan perbedaan yang tidak bermakna dan memberikan nilai positivitas yang rendah, sehingga berdasarkan data ini dapat disimpulkan pemeriksaan IgE RAST DR tidak dapat digunakan untuk membedakan kelompok penderita DA dengan kelompok non-DA.

Skin prick test TDR berkorelasi dengan nilai kemaknaan yang berarti terhadap pemeriksaan IgE RAST TDR pada kelompok DA dengan $\mathrm{p}=0,031$ (Tabel 4). Berdasarkan data tersebut dapat diartikan bahwa pemeriksaan SPT TDR pada penderita DA yang positif akan memberikan hasil positif pula pada pemeriksaan IgE RAST TDR.

Validitashasil pemeriksaan SPTTDR terhadap IgE RAST TDR pada penderita DA diketahui dari besarnya sensitivitas, spesifisitas, dan akurasi yang memberikan nilai berturut-turut $100 \%$, $25 \%$, dan $81 \%$, angka ini menunjukkan bila hasil SPT TDR positif dengan penderita menunjukkan 
gejala DA yang khas, maka penderita tersebut dapat didiagnosis pasti menderita DA (Tabel 5). Nilai sensitivitas SPT TDR 100\% menunjukkan bahwa pemeriksaan SPT TDR dapat digunakan sebagai uji tapis penyakit DA, namun validitas hasil pemeriksaan SPT DR pada penderita DA memberikan nilai sensitivitas yang rendah $43 \%$, spesifisitas $78 \%$, serta akurasi $63 \%$, sehingga SPT DR tidak dapat dipergunakan sebagai salah satu pemeriksaan penunjang untuk menegakkan diagnosis DA (Tabel 6).

Pada penderita DA faktor lingkungan yang utama yaitu paparan TDR, walaupun DR berperan mencetuskan DA. Debu rumah mengandung berbagai macam komponen selain TDR seperti serat, serbuk sari, sisa makanan, bakteri, jamur, tungau, dan serpihan kulit ari manusia. Pada penelitian ini ekstrak DR tidak mengandung TDR sehingga hasil SPT DR tidak menunjukkan hasil yang signifikan.

Nilai positivitas SPT TDR pada DA lebih tinggi daripada non-DA, serta memiliki korelasi dengan pemeriksaan IgE RAST TDR, sedangkan nilai positivitas SPT DR pada DA tidak lebih tinggi daripada non-DA, serta tidak memiliki korelasi dengan pemeriksaan IgE RAST DR. Hasil pemeriksaan SPT TDR terhadap IgE RAST TDR pada kelompok DA memberikan nilai validitas yang lebih tinggi dengan nilai sensitivitas sebesar $100 \%$, spesifisitas $25 \%$, dan akurasi $81 \%$, dibandingkan dengan SPT DR terhadap IgE RAST DR dengan nilai sensitivitas $43 \%$, spesifisitas $78 \%$, dan akurasi $63 \%$.

Simpulan, pemeriksaan SPT TDR dapat dijadikan sebagai patokan untuk mendiagnosis DA, karena hasil pemeriksaan SPT TDR yang positif dapat memberikan arti bahwa terdapat peningkatan IgE spesifik dengan pemeriksaan IgE RAST TDR.

\section{Daftar Pustaka}

1. Leung DYM, Eichenfield LF, Boguniewicz M. Atopic dermatitis. Dalam: Wolff K, Goldsmith LA, Katz SI, Gilchrest BA, Paller AS, Leffell DJ, penyunting. Fitzpatrick's dermatology in general medicine. Edisi ke7. New York: McGraw-Hill; 2006. hlm. $146-58$.

2. Williams HC. Clinical practice atopic dermatitis. $\mathrm{N}$ Engl $\mathrm{J}$ Med. 2005;352(22):2314-24.

3. Bieber T. Atopic dermatitis. N Engl J Med. 2008;358(14):1483-94.

4. Vickery BP. Skin barrier function in atopic dermatitis. Curr Opin Pediatr. 2007;19(1):89-93.
5. Suwarsa O. Aktivitas IL-18, IL-4, dan IFN- $\gamma$ pada kultur limfosit yang distimulus oleh Staphylococcal enterotoxin $B$ (SEB) sebagai petanda eksaserbasi tingkat seluler pada penderita dermatitis atopik [disertasi]. Bandung: Program Pascasarjana Universitas Padjadjaran; 2011.

6. Dahbi SM, Renz H. Role of inhalant allergens in atopic dermatitis. Dalam: Reitamo S, Luger TA, Steinhoff M, penyunting. Textbook of atopic dermatitis. London: Informa; 2008. hlm. 101-15.

7. Fuiano N, Fusilli S, Incorvaia C. House dust mite-related allergic diseases: role of skin prick test, atopy patch test, and RAST in the diagnostic of different manifestations of allergy. Eur J Pediatr. 2010;169(7):819-24.

8. Samochocki Z, Owczarek W, Zabielski S. Can atopy patch tests with aeroallergens be an additional diagnostic criterion for atopic dermatitis? Eur J Dermatol. 2006;16(2):151-4.

9. Novak N, Bieber T, Leung DYM. Immune mechanisms leading to atopic dermatitis. J Allergy Clin Immunol. 2003;112(6 Suppl):S128-39.

10. Erwin EA, Mills TA. Aeroallergens. Dalam: Bieber T, Leung DYM. penyunting. Atopic dermatitis. New York: Marcel Dekker; 2002. hlm. 357-74.

11. Visitsunthorn N, Pacharn $P$, Jirapongsananuruk $\mathrm{O}$, Weeravejsukit $\mathrm{S}$, Sookrung N, Bunnag C, dkk. Comparison between Siriraj mite allergen vaccine and standardized commercial mite vaccine by skin prick testing in normal Thai adults. Asian Pac J Allergy Immunol. 2010;28(1):41-5.

12. Witteman AM, Stapel SO, Perdok GJ, Sjamsoedin DH, Jansen HM, Aalberse RC, dkk. The relationship between RAST and skin test results in patients with asthma or rhinitis: a quantitative study with purified major allergens. J Allergy Clin Immunol. 1996;97(1 Pt 1):16-25.

13. Darsow U, Laifaoui J, Kerschenlohr K, Wollenberg A, Przybilla B, Wuthrich B. The prevalence of positive reactions in the atopy patch test with aeroallergens and food allergens in subjects with atopic eczema: a European multicenter study. Allergy. 2004;59(12):1318-25.

14. Johansson SG, Bieber $T$, Dahl $R$, Friedmann PS, Lanier BQ, Lockey RF, dkk. Revised nomenclature for allergy for global use: Report of the Nomenclature Review Committee of the World Allergy Organization, October 2003. J Allergy Clin Immunol. 2004;113(5):832-6. 
15. Terra SA, Silva DA, Sopelete MC, Mendes J, Sung SJ, Taketomi EA. Mite allergen levels and acarologic analysis in house dust samples in Uberaba, Brazil. J Investig Allergol Clin Immunol. 2004;14(3):232-7. 